\title{
ON NUMERICAL SOLUTION OF 1D POROELASTICITY EQUATIONS IN A MULTILAYERED DOMAIN
}

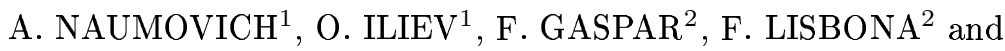 \\ P. VABISHCHEVICH ${ }^{3}$ \\ 1 Fraunhofer Institut fuer Techno- und Wirtschaftsmathematik \\ Gottlieb-Daimler Str. Geb.49, 67663 Kaiserslautern, Germany \\ E-mail: \{naumovic, iliev\}@itwm.fhg.de \\ 2 Dept. Applied Mathematics, University of Zaragoza \\ Pedro Cerbuna str. 12, 50009 Zaragoza, Spain \\ E-mail: \{fjgaspar, lisbona\}@posta.unizar.es \\ 3 Institute for Mathematical Modelling, Russian Academy of Science \\ Miusskaya sq. 4A, 125047 Moscow, Russia \\ E-mail: vab@rusal.ru
}

Received March 16, 2005; revised August 28, 2005

\begin{abstract}
Finite volume discretization of Biot system of poroelasticity in a multilayered domain is presented. Staggered grid is used in order to avoid non-physical oscillations of the numerical solution, appearing when a collocated grid is used. Various numerical experiments are presented in order to illustrate the accuracy of the finite difference scheme. In the first group of experiments, problems having analytical solutions are solved, and the order of convergence for the velocity, the pressure, the displacements, and the stresses is analyzed. In the second group of experiments numerical solution of real problems is presented.
\end{abstract}

Key words: poroelasticity, multilayered material, finite volume discretization, MAC type grid

\section{Introduction}

In soil mechanics assumption of only vertical subsidence is often invoked and this leads to the one-dimensional model of poroelasticity. The classical model of linear poroelasticity is obtained by Biot [3], detailed derivation can be found e.g., in [2]. This model is applicable also to modelling certain processes 
in geomechanics, hydrogeology, petroleum engineering (see, e.g., $[9,13]$ ), in biomechanics (e.g., $[1,10]$ ), in filtration (e.g., filter cake formation, see $[6,7$, 8]), etc.

Finite element and finite difference methods were applied by many authors for numerical solution of the Biot system of PDEs, see e.g. [4, 5, 9] and references therein. However, as it is well known, the standard FEM and FDM methods are subject to numerical instabilities at the first time steps. To avoid this, discretization on staggered grid was suggested in $[4,5]$. A single layer deformable porous medium was considered there.

This paper can be viewed as extension of $[4,5]$ to the case of multilayered deformable porous media. A finite volume discretization to the interface problem for the classical one-dimensional Biot model of consolidation process is applied here. The following assumptions are supposed to be valid: each of the porous layers is composed of incompressible solid matrix, it is homogeneous and isotropic. Furthermore, one of two following assumptions is valid: porous medium is not completely saturated and fluid is incompressible or porous medium is completely saturated and fluid is slightly compressible.

The reminder of the paper is organized as follows. Next section presents the mathematical model. Third section is devoted to the discretization of the continuous problem. Fourth section contains the results from the numerical experiments.

\section{Mathematical Model}

\subsection{Basic equations}

Classical Biot model of consolidation process for one-dimensional case consists of the system of two equations for unknown fluid pressure $p(x, t)$ and displacement of the solid skeleton $u(x, t)$

$$
\left\{\begin{array}{l}
-\frac{\partial}{\partial x}\left((\lambda+2 \mu) \frac{\partial u}{\partial x}\right)+\frac{\partial p}{\partial x}=0, \quad x \in(0, l), \quad t \in(0, T], \\
\frac{\partial}{\partial t}\left(\phi \beta p+\frac{\partial u}{\partial x}\right)-\frac{\partial}{\partial x}\left(\frac{k}{\eta} \frac{\partial p}{\partial x}\right)=q(x, t), \quad x \in(0, l), t \in(0, T],
\end{array}\right.
$$

where $\lambda$ and $\mu$ are Lame coefficients of the solid skeleton, $\phi$ is porosity, $\beta$ is compressibility coefficient of the fluid, $k$ is permeability of the porous medium, $\eta$ is viscosity of the fluid, $q(x, t)$ is a source term, which is used to describe forced extraction or injection process. Here we suppose that the solid grains are incompressible and the relative compressibility (Biot's coefficient) is identically equal to one.

Boundary conditions for (2.1) are the following:

$$
p=0, \quad(\lambda+2 \mu) \frac{\partial u}{\partial x}=-\sigma_{0}, \quad \text { if } x=0,
$$

what means that this boundary is free to drain and some stress is applied on it; another boundary condition is the following 


$$
u=0, \quad \frac{\partial p}{\partial x}=0, \quad \text { if } x=l
$$

what means that this boundary is rigid and impermeable. Initial condition

$$
\phi \beta p+\frac{\partial u}{\partial x}=0, \quad \text { for } t=0
$$

means that the variation in water content is zero at the beginning of the consolidation process.

Note that in the case of classical problem formulation $(2.1)-(2.4)$ (it describes fluid flow and skeleton deformation caused by the constant vertical load applied on the top of the column of soil, bounded with rigid and impermeable bottom and lateral walls and a top, which is free to drain), system (2.1) can be decoupled and then the problem can be solved separately for the fluid pressure and subsequently for solid displacements. But in general case system (2.1) might be supplemented with another types of boundary conditions, corresponding to different physical phenomena on the boundaries, what makes decoupling impossible and simultaneous solution must be sought both for pore pressure and displacement of the solid matrix. In this paper we deal with the coupled model, what makes our approach more general and universal for modeling of the consolidation process.

\subsection{Interface problem}

Consider a multilayered porous medium, where each of the layers has different physical properties. We are interested in the coupled fluid flow in the porous medium and in deformations of the porous medium when certain stress is applied to it. In this case, in addition to the basic equations given above, we have to consider interface transmission closing conditions for (2.1) on the interface between different layers. In the assumption of a perfect contact and a two-layer medium, the interface conditions look as follows

$$
[u]=0,\left[(\lambda+2 \mu) \frac{\partial u}{\partial x}\right]=0,[p]=0,\left[\frac{k}{\eta} \frac{\partial p}{\partial x}\right]=0 \text { for } x=\zeta, t \in[0, T],
$$

where $0 \leq \zeta \leq l$ is the position of the interface between the two layers.

The coefficients of the governing equations are discontinuous across the interface, i.e.

$$
\lambda=\left\{\begin{array}{ll}
\lambda_{1}, & x<\zeta, \\
\lambda_{2}, & x>\zeta,
\end{array} \quad \mu=\left\{\begin{array}{ll}
\mu_{1}, & x<\zeta, \\
\mu_{2}, & x>\zeta,
\end{array} \quad k=\left\{\begin{array}{ll}
k_{1}, & x<\zeta, \\
k_{2}, & x>\zeta,
\end{array} \quad \phi= \begin{cases}\phi_{1}, & x<\zeta, \\
\phi_{2}, & x>\zeta\end{cases}\right.\right.\right.
$$

Interface conditions (2.5) mean continuity of the displacements and the stress of the solid, as well as continuity of the pressure and the velocity of the fluid across the interface between the two layers.

Let us transform the governing equations and the interface conditions to dimensionless form. The following scales are introduced 


$$
\begin{aligned}
& x:=\frac{x}{l}, \quad t:=\frac{\left(\lambda_{0}+2 \mu_{0}\right) k_{0} t}{\eta l^{2}}, \quad p:=\frac{p}{\sigma_{0}}, \\
& u:=\frac{\left(\lambda_{0}+2 \mu_{0}\right) u}{\sigma_{0} l}, \quad \nu:=\frac{\lambda+2 \mu}{\lambda_{0}+2 \mu_{0}}, \quad k:=\frac{k}{k_{0}},
\end{aligned}
$$

where $\lambda_{0}, \mu_{0}, k_{0}$ are some reference values. Then, we introduce notation

$$
a=\phi \beta\left(\lambda_{0}+2 \mu_{0}\right), \quad f(x, t)=\frac{l^{2} \eta}{\sigma_{0} k_{0}} q(x, t)
$$

and write the problem in the following way:

$$
\left\{\begin{array}{l}
-\frac{\partial}{\partial x}\left(\nu \frac{\partial u}{\partial x}\right)+\frac{\partial p}{\partial x}=0, x \in(0,1), t \in(0, T] \\
\frac{\partial}{\partial t}\left(a p+\frac{\partial u}{\partial x}\right)-\frac{\partial}{\partial x}\left(k \frac{\partial p}{\partial x}\right)=f(x, t), x \in(0,1), t \in(0, T] \\
\nu \frac{\partial u}{\partial x}=-1, p=0, \text { if } x=0, t \in(0, T] \\
u=0, \frac{\partial p}{\partial x}=0, \text { if } x=1, t \in(0, T] \\
a p+\frac{\partial u}{\partial x}=0, \text { if } t=0, x \in(0,1), \\
{[u]=0,\left[\nu \frac{\partial u}{\partial x}\right]=0,[p]=0,\left[k \frac{\partial p}{\partial x}\right]=0 \text { for } x=\zeta, t \in(0, T]}
\end{array}\right.
$$

\section{MAC Type Grids and Finite Volume Discretization}

We split the interval $(0,1)$ into $N>1$ equal subintervals of size $h=\frac{2}{(2 N-1)}$. We use different spatial grids (so-called staggered grids), $\bar{\omega}_{p}$ to discretize with respect to pressure, and $\bar{\omega}_{u}$ to discretize with respect to displacement, and a grid in time $t$ with a step-size $\tau$ :

$$
\begin{aligned}
& \bar{\omega}_{p}=\left\{x_{i}: x_{i}=i h, i=0, \ldots, N-1\right\}, \\
& \bar{\omega}_{u}=\left\{\xi_{i}: \xi_{i}=x_{i}-0.5 h, i=1, \ldots, N\right\}, \\
& \omega_{T}=\left\{t_{j}: t_{j}=j \tau, j=1,2, \ldots, M\right\} .
\end{aligned}
$$

One may consider these grids as designed to represent the values of the pressure $p$ at the grid points $x_{i} \in \bar{\omega}_{p}$ and the values of the displacement $u$ at the midpoints $\xi_{i} \in \bar{\omega}_{u}$ of the subintervals $\left(x_{i-1}, x_{i}\right)$. The position of the interface $\zeta$ can be represented in the form $\zeta=\xi_{n}+\theta h$, where $0<n<N$ is an integer and $0 \leq \theta<1$.

Now we shall introduce the following shorthand notations for discrete functions defined on $\bar{\omega}_{p} \times \omega_{T}$ and $\bar{\omega}_{u} \times \omega_{T}$, respectively: 


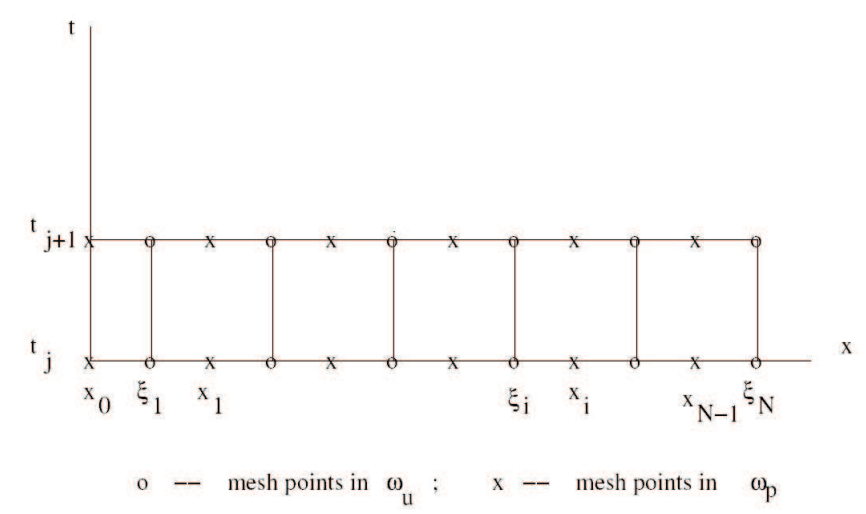

Figure 1. Grids $\omega_{p}, \omega_{u}$ and $\omega_{T}$.

$$
\begin{aligned}
& u:=u^{j}:=u_{i}^{j}:=u\left(\xi_{i}, t_{j}\right), \quad p:=p^{j}:=p_{i}^{j}:=p\left(x_{i}, t_{j}\right), \\
& v^{\sigma}:=\sigma v^{j+1}+(1-\sigma) v^{j}, \quad \hat{v}:=v^{j+1}
\end{aligned}
$$

Further, we shall use the standard notation of the first order backward and forward finite differences on a uniform grid (see, e.g. [12]):

$$
p_{x}:=p_{x, i}=\frac{p\left(x_{i+1}\right)-p\left(x_{i}\right)}{h}, \quad p_{\bar{x}}:=p_{\bar{x}, i}=\frac{p\left(x_{i}\right)-p\left(x_{i-1}\right)}{h} .
$$

Inspecting these expressions we see that these differences represent central differences with respect to the points of $\omega_{u}$ and therefore we can easily accept that they represent quantities defined on the grid $\omega_{u}$. In a similar way we define

$$
u_{x}:=u_{x, i}=\frac{u\left(\xi_{i+1}\right)-u\left(\xi_{i}\right)}{h}, \quad u_{\bar{x}}:=u_{\bar{x}, i}=\frac{u\left(\xi_{i}\right)-u\left(\xi_{i-1}\right)}{h},
$$

which represent central differences with respect to the points of $\omega_{p}$ and therefore they represent quantities defined on the grid $\omega_{p}$. Finally, we define the finite differences in time direction

$$
u_{t}:=u_{t}\left(\xi_{i}, t_{j}\right)=\frac{u_{i}^{j+1}-u_{i}^{j}}{\tau}, \xi_{i} \in \omega_{u}, \quad p_{t}:=p_{t}\left(x_{i}, t_{j}\right)=\frac{p_{i}^{j+1}-p_{i}^{j}}{\tau}, x_{i} \in \omega_{p} .
$$

Following the basic principles of the finite volume method (method of balance, [12]), we write balance equations for the first equation of system (2.6) over each volume $V_{\xi_{i}}=\left(x_{i-1}, x_{i}\right)$

$$
-\int_{x_{i-1}}^{x_{i}} \frac{\partial}{\partial x}\left(\nu \frac{\partial u}{\partial x}\right) d x+\int_{x_{i-1}}^{x_{i}} \frac{\partial p}{\partial x} d x=0
$$

and for the second equation of (2.6) over each volume $V_{x_{i}}=\left(\xi_{i}, \xi_{i+1}\right)$ 


$$
\int_{\xi_{i}}^{\xi_{i+1}} \frac{\partial}{\partial t}\left(a p+\frac{\partial u}{\partial x}\right) d x-\int_{\xi_{i}}^{\xi_{i+1}} \frac{\partial}{\partial x}\left(k \frac{\partial p}{\partial x}\right) d x=\int_{\xi_{i}}^{\xi_{i+1}} f(x, t) d x .
$$

Consider balance equations (3.1), (3.2) and replace integrals in these equations by the following difference expressions

$$
\begin{aligned}
& \int_{x_{i-1}}^{x_{i}} \frac{\partial}{\partial x}\left(\nu \frac{\partial u}{\partial x}\right) d x \approx h\left(\nu u_{\bar{x}}\right)_{x, i}, \quad \int_{\xi_{i}}^{\xi_{i+1}} \frac{\partial}{\partial x}\left(k \frac{\partial p}{\partial x}\right) d x \approx h\left(k p_{\bar{x}}^{\sigma}\right)_{x, i}, \\
& \int_{\xi_{i}}^{\xi_{i+1}} \frac{\partial}{\partial t}\left(a p+\frac{\partial u}{\partial x}\right) d x \approx h\left(a_{i} p_{i}+u_{x, i}\right)_{t}, \quad \int_{x_{i-1}}^{x_{i}} \frac{\partial p}{\partial x} d x \approx h p_{\bar{x}, i},
\end{aligned}
$$

where

$$
\nu_{i}=\left(\frac{1}{h} \int_{\xi_{i}}^{\xi_{i+1}} \frac{d x}{\nu(x)}\right)^{-1}, \quad a_{i}=\int_{\xi_{i}}^{\xi_{i+1}} a(x) d x, \quad k_{i}=\left(\frac{1}{h} \int_{x_{i-1}}^{x_{i}} \frac{d x}{k(x)}\right)^{-1}
$$

and $0 \leq \sigma \leq 1$ is some weight factor. Note, that during the approximation of integrals above we applied harmonic averaging for coefficients $\nu(x)$ and $k(x)$.

Substituting approximate expressions of integrals into balance equations (3.1) and (3.2) and using non-index notations, we obtain a finite-difference scheme for problem $(2.6)$ :

$$
\begin{aligned}
& -\frac{\nu}{h} \hat{u}_{x}+\hat{p}_{\bar{x}}=\frac{1}{h}, \quad \xi=\xi_{1}, \quad t \in \omega_{T} \quad(i . e . i=1), \\
& -\left(\nu \hat{u}_{\bar{x}}\right)_{x}+\hat{p}_{\bar{x}}=0, \quad \xi=\xi_{i} \in \omega_{u} \backslash\left\{\xi_{1}\right\}, \quad t \in \omega_{T} \quad(i . e . i=2, \ldots, N-1), \\
& \begin{array}{r}
\left(a p+u_{x}\right)_{t}-\left(k p_{\bar{x}}^{\sigma}\right)_{x}=f^{\sigma}, \quad x=x_{i} \in \omega_{p} \backslash\left\{x_{N-1}\right\}, \\
\\
\quad t \in \omega_{T} \quad(i . e . i=1, \ldots, N-2),
\end{array} \\
& \begin{aligned}
\left(a p+u_{x}\right)_{t}-\frac{k}{h} p_{\bar{x}}^{\sigma}=f^{\sigma}, \quad x=x_{N-1}, \quad t \in \omega_{T} \quad(i . e . i=N-1), \\
p_{0}=0, \quad u_{N}=0, \quad t \in \omega_{T},
\end{aligned} \\
& a p+u_{x}=0, \quad x=x_{i} \in \bar{\omega}_{p}, \quad t=0 \quad(\text { i.e. } i=1, \ldots, N-1),
\end{aligned}
$$

where coefficients $\nu, a$ and $k$ are defined by formulae (3.3), and the right hand side is calculated as

$$
f_{i}=\frac{1}{h} \int_{\xi_{i}}^{\xi_{i+1}} f(x, t) d x
$$


One can show that in the case of piecewise-constant coefficients $\nu(x), k(x)$ and $a(x)$ formulae (3.3) give us the following expressions for coefficients

$$
\begin{aligned}
& \nu_{i}=\left\{\begin{aligned}
\nu_{1}, & i=0, \ldots, n-1, \\
\frac{\nu_{1} \nu_{2}}{(1-\theta) \nu_{1}+\theta \nu_{2}}, & i=n \\
\nu_{2}, & i=n+1, \ldots, N-1,
\end{aligned}\right. \\
& a_{i}=\left\{\begin{aligned}
a_{1}, & i=0, \ldots, n-1, \\
\theta a_{1}+(1-\theta) a_{2}, & i=n, \\
a_{2}, & i=n+1, \ldots, N-1,
\end{aligned}\right. \\
& k_{i}=\left\{\begin{aligned}
k_{1}, & i=1, \ldots, n-1, & \\
\frac{k_{1} k_{2}}{(0.5-\theta) k_{1}+(0.5+\theta) k_{2}}, & i=n, & \text { for } \theta \leq 0.5 \\
k_{2}, & i=n+1, \ldots, N, &
\end{aligned}\right. \\
& k_{i}=\left\{\begin{aligned}
k_{1}, & i=1, \ldots, n, \\
\frac{k_{1} k_{2}}{(1.5-\theta) k_{1}+(\theta-0.5) k_{2}}, & i=n+1 \quad \text { for } \theta>0.5 . \\
k_{2}, & i=n+2, \ldots, N .
\end{aligned}\right.
\end{aligned}
$$

To solve the system arisen after the discretization we use the block TDMA (see, e.g. [12]).

In the case of continuous coefficients (single layered porous media), the second order convergence in operator norms is proven in [4]. Theoretical analysis of (2.6) in the case of discontinuous coefficients is in progress and will be reported in a forthcoming paper.

\section{Numerical Results}

Let us consider the initial boundary value problem, IBVP, (2.6), which describes deformation and fluid flow in the column, consisting of two layers of soils with different physical properties. The top of this column is free to drain, and some load is applied on it, the bottom is impermeable and rigid. We are interested in the following physical characteristics of this process: fluid pressure, fluid velocity, displacements of the solid skeleton and stresses therein. Two sets of numerical experiments were carried out in order to study numerically the performance of the above described discretization (3.4): Case $A$ : IBVP with known analytical solution and Case $B$ : IBVP with no analytical solution known. 


\section{Case A: IBVP with known analytical solution}

In the first set, three experiments were performed in order to study numerically the convergence rate of the scheme (3.4). Incompressible and compressible cases are considered, as well as larger or smaller jumps of the coefficients. In our tests we compare obtained numerical solutions with the known analytical solutions and calculate relative discrete $L_{2}$ and maximum $C$ norms of solution errors:

$$
\left\|\epsilon_{w}\right\|_{C}=\frac{\max _{x_{i} \in \omega_{\bar{w}}}\left|w^{e x}\left(x_{i}, t_{j}\right)-w_{i}^{a p p}\right|}{\max _{x_{i} \in \omega_{\bar{w}}}\left|w^{e x}\left(x_{i}, t_{j}\right)\right|},\left\|\epsilon_{w}\right\|_{L_{2}}=\frac{\sum_{x_{i} \in \omega_{\bar{w}}} h\left|w^{e x}\left(x_{i}, t_{j}\right)-w_{i}^{a p p}\right|}{\max _{\omega_{\bar{w}}}\left|w^{e x}\left(x_{i}, t_{j}\right)\right|},
$$

where $w^{e x}$ and $w^{a p p}$ stand for the analytical and numerical solutions respectively, and $w=\{u, p, v, s\}$. We use the weight parameter $\sigma=0.5$, what allows us to obtain the second order of convergence in time.

Example 1. For the first test we choose the following values of the coefficients:

$$
\begin{aligned}
& \nu_{1}=1, \quad \nu_{2}=\frac{\tan \left(\frac{1}{12}\right) \tan \left(\frac{10 \pi}{3}\right)}{8 \pi} \approx 0.0058, \quad k_{1}=1, \\
& k_{2}=\frac{1}{8 \pi \tan \left(\frac{1}{12}\right) \tan \left(\frac{10 \pi}{3}\right)} \approx 0.275, a_{1}=0, \quad a_{2}=0, \quad f(x, t)=0 .
\end{aligned}
$$

Position of the interface between two media is given by $\zeta=\frac{1}{6}$. Then the exact solution of a problem like (2.6), but in the case of homogeneous boundary conditions and another initial conditions, is given by

$$
\begin{gathered}
p(x, t)= \begin{cases}\cos \left(\frac{10 \pi}{3}\right) \sin (0.5 x) e^{-0.25 t}, & x \leq \frac{1}{6}, \\
\sin \left(\frac{1}{12}\right) \cos (4 \pi(1-x)) e^{-0.25 t}, & x>\frac{1}{6},\end{cases} \\
u(x, t)= \begin{cases}-2 \cos \left(\frac{10 \pi}{3}\right) \cos (0.5 x) e^{-0.25 t}, & x \leq \frac{1}{6}, \\
-\frac{2 \cos \left(\frac{1}{12}\right)}{\tan \left(\frac{10 \pi}{3}\right)} \sin \left(\frac{1}{12}\right) \sin (4 \pi(1-x)) e^{-0.25 t}, & x>\frac{1}{6} .\end{cases}
\end{gathered}
$$

The initial conditions are calculated from the above formulae at $t=0$. Analytical expressions for the fluid velocity and for the stress of the solid are calculated from the Darcy law $v(x, t)=-k \frac{\partial p(x, t)}{\partial x}$ and from the stress-strain relationship $s(x, t)=\nu \frac{\partial u(x, t)}{\partial x}$.

Convergence results are summarized in Tables 1-4. Note, that the grid steps are decreased in such a way, that a constant value of the parameter $\theta$ 
is preserved in the expression $\zeta=x_{n-0.5}+\theta h$. Convergence results in the tables are presented for two time moments $t=0.1$ and $t=1.0$. It follows from the presented results that there is no big change in the errors at the two monitored time levels. Existing theoretical error estimates for this problem (see, e.g. [4] for the case of continuous coefficients), predict dependence of the error on time. Thus these theoretical estimates are severely overestimating the error in our case.

Table 1. Example 1: convergence in the $L_{2}$-norm at $t=0.1$.

\begin{tabular}{llcccc}
\hline$h$ & $\tau$ & $\left\|\epsilon_{u}\right\|_{L_{2}}$ & $\left\|\epsilon_{p}\right\|_{L_{2}}$ & $\left\|\epsilon_{v}\right\|_{L_{2}}$ & $\left\|\epsilon_{s}\right\|_{L_{2}}$ \\
\hline $1 / 10$ & $1 / 10$ & $0.222 \mathrm{E}-02$ & $0.155 \mathrm{E} 00$ & $0.130 \mathrm{E} 00$ & $0.739 \mathrm{E}-01$ \\
$1 / 40$ & $1 / 40$ & $0.508 \mathrm{E}-03$ & $0.243 \mathrm{E}-01$ & $0.153 \mathrm{E}-01$ & $0.106 \mathrm{E}-01$ \\
$1 / 160$ & $1 / 160$ & $0.368 \mathrm{E}-04$ & $0.105 \mathrm{E}-02$ & $0.789 \mathrm{E}-03$ & $0.488 \mathrm{E}-03$ \\
$1 / 640$ & $1 / 640$ & $0.222 \mathrm{E}-05$ & $0.634 \mathrm{E}-04$ & $0.639 \mathrm{E}-04$ & $0.298 \mathrm{E}-04$ \\
$1 / 2560$ & $1 / 2560$ & $0.137 \mathrm{E}-06$ & $0.393 \mathrm{E}-05$ & $0.657 \mathrm{E}-05$ & $0.185 \mathrm{E}-05$ \\
\hline
\end{tabular}

Table 2. Example 1: convergence in the $L_{2}$-norm at $t=1$.

\begin{tabular}{llcccc}
\hline$h$ & $\tau$ & $\left\|\epsilon_{u}\right\|_{L_{2}}$ & $\left\|\epsilon_{p}\right\|_{L_{2}}$ & $\left\|\epsilon_{v}\right\|_{L_{2}}$ & $\left\|\epsilon_{s}\right\|_{L_{2}}$ \\
\hline $1 / 10$ & $1 / 10$ & $0.276 \mathrm{E}-01$ & $0.559 \mathrm{E}-01$ & $0.737 \mathrm{E}-01$ & $0.273 \mathrm{E}-01$ \\
$1 / 40$ & $1 / 40$ & $0.178 \mathrm{E}-02$ & $0.248 \mathrm{E}-02$ & $0.399 \mathrm{E}-02$ & $0.156 \mathrm{E}-02$ \\
$1 / 160$ & $1 / 160$ & $0.107 \mathrm{E}-03$ & $0.157 \mathrm{E}-03$ & $0.248 \mathrm{E}-03$ & $0.973 \mathrm{E}-04$ \\
$1 / 640$ & $1 / 640$ & $0.662 \mathrm{E}-05$ & $0.977 \mathrm{E}-05$ & $0.159 \mathrm{E}-04$ & $0.607 \mathrm{E}-05$ \\
$1 / 2560$ & $1 / 2560$ & $0.413 \mathrm{E}-06$ & $0.610 \mathrm{E}-06$ & $0.110 \mathrm{E}-05$ & $0.379 \mathrm{E}-06$ \\
\hline
\end{tabular}

Table 3. Example 1: convergence in the maximum norm at $t=0.1$.

\begin{tabular}{llcccc}
\hline$h$ & $\tau$ & $\left\|\epsilon_{u}\right\|_{c}$ & $\left\|\epsilon_{p}\right\|_{c}$ & $\left\|\epsilon_{v}\right\|_{c}$ & $\left\|\epsilon_{s}\right\|_{c}$ \\
\hline $1 / 10$ & $1 / 10$ & $0.518 \mathrm{E}-02$ & $0.226 \mathrm{E}+00$ & $0.322 \mathrm{E}+00$ & $0.196 \mathrm{E}+00$ \\
$1 / 40$ & $1 / 40$ & $0.306 \mathrm{E}-02$ & $0.304 \mathrm{E}-01$ & $0.833 \mathrm{E}-01$ & $0.273 \mathrm{E}-01$ \\
$1 / 160$ & $1 / 160$ & $0.337 \mathrm{E}-03$ & $0.139 \mathrm{E}-02$ & $0.470 \mathrm{E}-02$ & $0.114 \mathrm{E}-02$ \\
$1 / 640$ & $1 / 640$ & $0.224 \mathrm{E}-04$ & $0.841 \mathrm{E}-04$ & $0.107 \mathrm{E}-02$ & $0.712 \mathrm{E}-04$ \\
$1 / 2560$ & $1 / 2560$ & $0.142 \mathrm{E}-05$ & $0.522 \mathrm{E}-05$ & $0.262 \mathrm{E}-03$ & $0.442 \mathrm{E}-05$ \\
\hline
\end{tabular}

From numerical experiments we conclude that displacement, pressure and stress converge with the second order in time and space in both $L_{2}$ and $C$ norms. The fluid velocity converges with second order in $L_{2}$ norm, and with 
Table 4. Example 1: convergence in the maximum norm at $t=1$.

\begin{tabular}{llcccc}
\hline$h$ & $\tau$ & $\left\|\epsilon_{u}\right\|_{c}$ & $\left\|\epsilon_{p}\right\|_{c}$ & $\left\|\epsilon_{v}\right\|_{c}$ & $\left\|\epsilon_{s}\right\|_{c}$ \\
\hline $1 / 10$ & $1 / 10$ & $0.645 \mathrm{E}-01$ & $0.963 \mathrm{E}-01$ & $0.145 \mathrm{E}+00$ & $0.581 \mathrm{E}-01$ \\
$1 / 40$ & $1 / 40$ & $0.620 \mathrm{E}-02$ & $0.481 \mathrm{E}-02$ & $0.619 \mathrm{E}-02$ & $0.277 \mathrm{E}-02$ \\
$1 / 160$ & $1 / 160$ & $0.382 \mathrm{E}-03$ & $0.284 \mathrm{E}-03$ & $0.387 \mathrm{E}-03$ & $0.151 \mathrm{E}-03$ \\
$1 / 640$ & $1 / 640$ & $0.238 \mathrm{E}-04$ & $0.174 \mathrm{E}-04$ & $0.832 \mathrm{E}-04$ & $0.913 \mathrm{E}-05$ \\
$1 / 2560$ & $1 / 2560$ & $0.148 \mathrm{E}-05$ & $0.108 \mathrm{E}-05$ & $0.210 \mathrm{E}-04$ & $0.566 \mathrm{E}-06$ \\
\hline
\end{tabular}
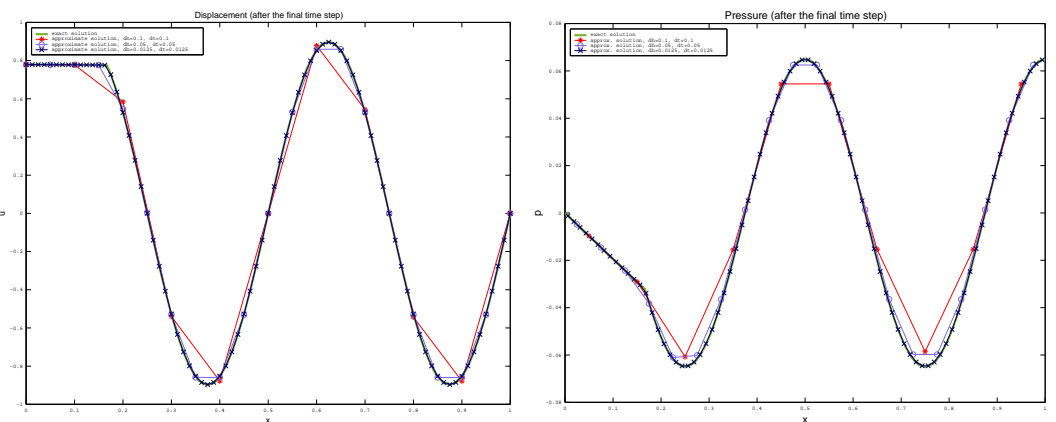

Figure 2. Example 1: convergence of displacement (left) and pressure (right).
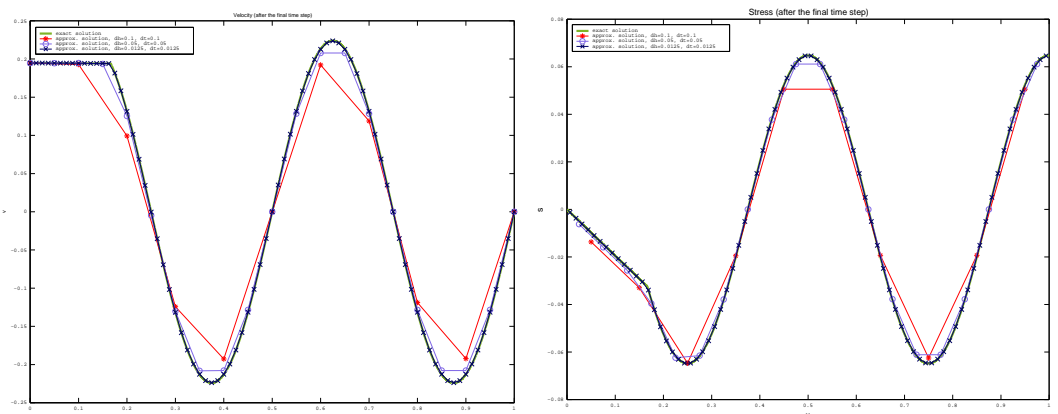

Figure 3. Example 1: convergence of velocity (left) and stress (right).

first order in the maximum norm. On very coarse grids velocity converges with higher than first order in the maximum norm. The reason is that these grids are far from the asymptotic regime.

Fig. 2 and 3 represent the analytical and numerical solutions calculated on different grids. Fig.4 illustrates these convergence orders.

Example 2. In the second test we consider compressible fluid ( $a_{1}$ and $a_{2}$ are nonzero). The following values for the coefficients are used: 

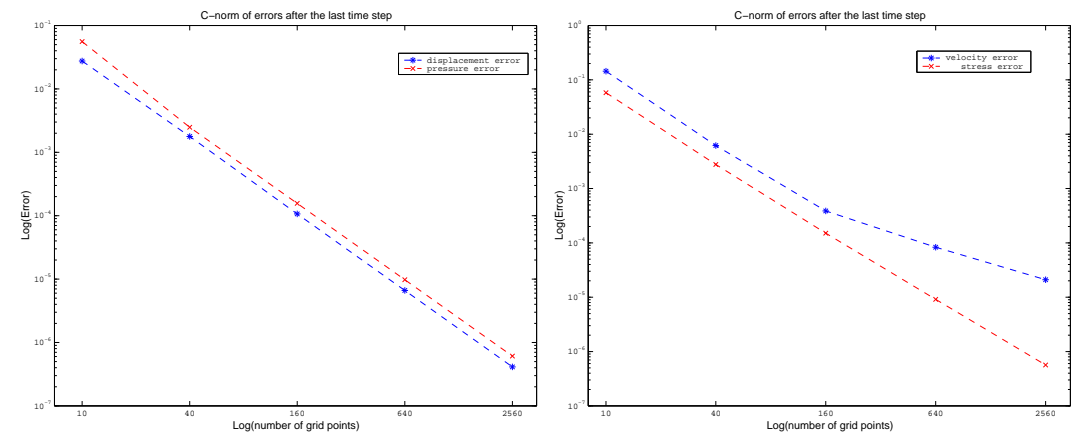

Figure 4. Example 1: errors in the maximum norm for pressure and displacement (left) and velocity and stress (right).

$$
\begin{aligned}
& \nu_{1}=1, \quad \nu_{2}=\frac{\tan \left(\frac{2}{3}\right) \tan \left(\frac{10}{3}\right)}{10} \approx 0.0153, \quad k_{1}=1, \quad f(x, t)=0, \\
& k_{2}=\frac{1}{10 \tan \left(\frac{2}{3}\right) \tan \left(\frac{10}{3}\right)} \approx 0.6547, a_{1}=0.01, a_{2}=\frac{10.1}{\tan \left(\frac{2}{3}\right) \tan \left(\frac{10}{3}\right)} \approx 66.1227 .
\end{aligned}
$$

Position of the interface is $\zeta=\frac{2}{3}$. Exact solution is given by

$$
\begin{gathered}
p(x, t)= \begin{cases}\cos \left(\frac{10}{3}\right) \sin (x) e^{-\frac{100}{101} t}, & x \leq \frac{2}{3}, \\
\sin \left(\frac{2}{3}\right) \cos (10(1-x)) e^{-\frac{100}{101} t}, & x>\frac{2}{3},\end{cases} \\
u(x, t)= \begin{cases}-\cos \left(\frac{10}{3}\right) \cos (x) e^{-\frac{100}{101} t}, & x \leq \frac{2}{3}, \\
-\frac{1}{10 \tan \left(\frac{2}{3}\right) \tan \left(\frac{10}{3}\right)} \sin \left(\frac{2}{3}\right) \sin (10(1-x)) e^{-\frac{100}{101} t}, & x>\frac{2}{3} .\end{cases}
\end{gathered}
$$

Convergence results for Example 2 are summarized in Tables 5-8. The convergence orders for the compressible case are the same as for the incompressible as it is illustrated in Fig.6. Analytical and numerical solutions, calculated on different grides are plotted on Fig.5.

Example 3. In the third test we consider again incompressible fluid, but the ratio between coefficients $k_{1}$ and $k_{2}$ is large (about four orders of magnitude). The values for the coefficients are the following:

$$
\begin{aligned}
& \nu_{1}=1, \quad \nu_{2}=\frac{1}{100} \tan \left(\frac{8}{15}\right) \tan \left(\frac{80}{3}\right) \approx 0.1601, \quad k_{1}=1, \\
& k_{2}=\frac{1}{\tan \left(100 \frac{8}{15}\right) \tan \left(\frac{80}{3}\right)} \approx 6.2479 \cdot 10^{-4}, \quad a_{1}=0, a_{2}=0, \quad f(x, t)=0 .
\end{aligned}
$$


298 A. Naumovich, O. Iliev, F. Gaspar, F. Lisbona, P. Vabishchevich

Table 5. Example 2: convergence in the maximum norm at $t=0.1$.

\begin{tabular}{llcccc}
\hline$h$ & $\tau$ & $\left\|\epsilon_{u}\right\|_{c}$ & $\left\|\epsilon_{p}\right\|_{c}$ & $\left\|\epsilon_{v}\right\|_{c}$ & $\left\|\epsilon_{s}\right\|_{c}$ \\
\hline $1 / 10$ & $1 / 10$ & $0.542 \mathrm{E}-02$ & $0.270 \mathrm{E}-01$ & $0.696 \mathrm{E}-01$ & $0.308 \mathrm{E}-01$ \\
$1 / 40$ & $1 / 40$ & $0.116 \mathrm{E}-02$ & $0.210 \mathrm{E}-02$ & $0.468 \mathrm{E}-02$ & $0.209 \mathrm{E}-02$ \\
$1 / 160$ & $1 / 160$ & $0.730 \mathrm{E}-04$ & $0.151 \mathrm{E}-03$ & $0.581 \mathrm{E}-03$ & $0.139 \mathrm{E}-03$ \\
$1 / 640$ & $1 / 640$ & $0.453 \mathrm{E}-05$ & $0.963 \mathrm{E}-05$ & $0.132 \mathrm{E}-03$ & $0.907 \mathrm{E}-05$ \\
$1 / 2560$ & $1 / 2560$ & $0.282 \mathrm{E}-06$ & $0.608 \mathrm{E}-06$ & $0.322 \mathrm{E}-04$ & $0.575 \mathrm{E}-06$ \\
\hline
\end{tabular}

Table 6. Example 2: convergence in the maximum norm at $t=1$.

\begin{tabular}{llcccc}
\hline$h$ & $\tau$ & $\left\|\epsilon_{u}\right\|_{c}$ & $\left\|\epsilon_{p}\right\|_{c}$ & $\left\|\epsilon_{v}\right\|_{c}$ & $\left\|\epsilon_{s}\right\|_{c}$ \\
\hline $1 / 10$ & $1 / 10$ & $0.631 \mathrm{E}-01$ & $0.621 \mathrm{E}-01$ & $0.301 \mathrm{E}-01$ & $0.422 \mathrm{E}-01$ \\
$1 / 40$ & $1 / 40$ & $0.471 \mathrm{E}-02$ & $0.423 \mathrm{E}-02$ & $0.183 \mathrm{E}-02$ & $0.231 \mathrm{E}-02$ \\
$1 / 160$ & $1 / 160$ & $0.300 \mathrm{E}-03$ & $0.265 \mathrm{E}-03$ & $0.107 \mathrm{E}-03$ & $0.149 \mathrm{E}-03$ \\
$1 / 640$ & $1 / 640$ & $0.188 \mathrm{E}-04$ & $0.165 \mathrm{E}-04$ & $0.206 \mathrm{E}-04$ & $0.937 \mathrm{E}-05$ \\
$1 / 2560$ & $1 / 2560$ & $0.118 \mathrm{E}-05$ & $0.103 \mathrm{E}-05$ & $0.477 \mathrm{E}-05$ & $0.586 \mathrm{E}-06$ \\
\hline
\end{tabular}

Table 7. Example 2: convergence in $L_{2}$ norm at $t=0.1$.

\begin{tabular}{llcccc}
\hline$h$ & $\tau$ & $\left\|\epsilon_{u}\right\|_{L_{2}}$ & $\left\|\epsilon_{p}\right\|_{L_{2}}$ & $\left\|\epsilon_{v}\right\|_{L_{2}}$ & $\left\|\epsilon_{s}\right\|_{L_{2}}$ \\
\hline $1 / 10$ & $1 / 10$ & $0.289 \mathrm{E}-02$ & $0.128 \mathrm{E}-01$ & $0.358 \mathrm{E}-01$ & $0.139 \mathrm{E}-01$ \\
$1 / 40$ & $1 / 40$ & $0.275 \mathrm{E}-03$ & $0.938 \mathrm{E}-03$ & $0.194 \mathrm{E}-02$ & $0.861 \mathrm{E}-03$ \\
$1 / 160$ & $1 / 160$ & $0.163 \mathrm{E}-04$ & $0.689 \mathrm{E}-04$ & $0.125 \mathrm{E}-03$ & $0.641 \mathrm{E}-04$ \\
$1 / 640$ & $1 / 640$ & $0.101 \mathrm{E}-05$ & $0.443 \mathrm{E}-05$ & $0.931 \mathrm{E}-05$ & $0.419 \mathrm{E}-05$ \\
$1 / 2560$ & $1 / 2560$ & $0.627 \mathrm{E}-07$ & $0.279 \mathrm{E}-06$ & $0.859 \mathrm{E}-06$ & $0.264 \mathrm{E}-06$ \\
\hline
\end{tabular}

Table 8. Example 2: convergence in $L_{2}$ norm at $t=1$.

\begin{tabular}{llcccc}
\hline$h$ & $\tau$ & $\left\|\epsilon_{u}\right\|_{L_{2}}$ & $\left\|\epsilon_{p}\right\|_{L_{2}}$ & $\left\|\epsilon_{v}\right\|_{L_{2}}$ & $\left\|\epsilon_{s}\right\|_{L_{2}}$ \\
\hline $1 / 10$ & $1 / 10$ & $0.277 \mathrm{E}-01$ & $0.219 \mathrm{E}-01$ & $0.967 \mathrm{E}-02$ & $0.206 \mathrm{E}-01$ \\
$1 / 40$ & $1 / 40$ & $0.183 \mathrm{E}-02$ & $0.169 \mathrm{E}-02$ & $0.530 \mathrm{E}-03$ & $0.152 \mathrm{E}-02$ \\
$1 / 160$ & $1 / 160$ & $0.117 \mathrm{E}-03$ & $0.108 \mathrm{E}-03$ & $0.324 \mathrm{E}-04$ & $0.974 \mathrm{E}-04$ \\
$1 / 640$ & $1 / 640$ & $0.733 \mathrm{E}-05$ & $0.681 \mathrm{E}-05$ & $0.217 \mathrm{E}-05$ & $0.613 \mathrm{E}-05$ \\
$1 / 2560$ & $1 / 2560$ & $0.459 \mathrm{E}-06$ & $0.426 \mathrm{E}-06$ & $0.171 \mathrm{E}-06$ & $0.384 \mathrm{E}-06$ \\
\hline
\end{tabular}



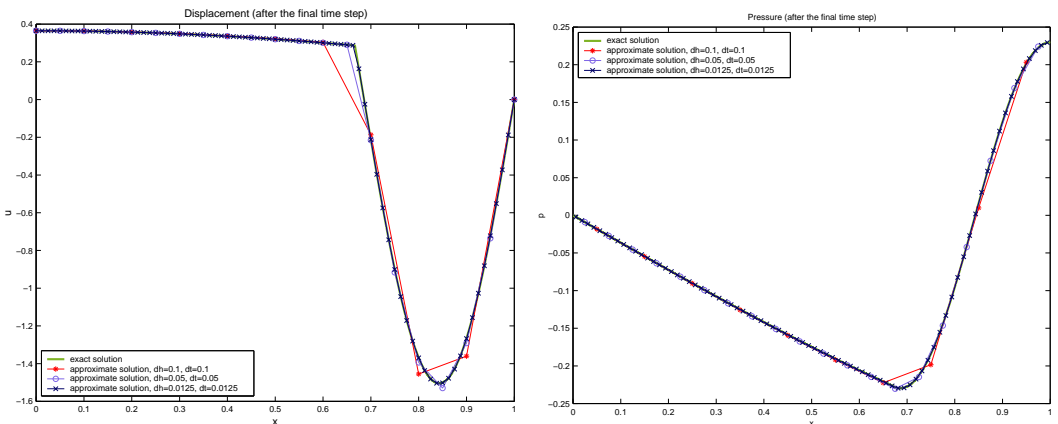

Figure 5. Example 2: Convergence of displacement (left) and pressure (right).
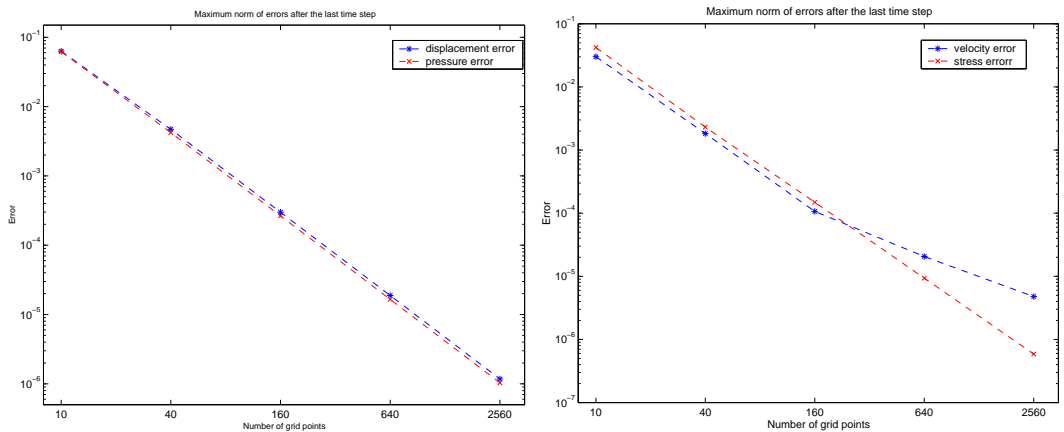

Figure 6. Example 2: Errors in the maximum norm for pressure and displacement (left) and velocity and stress (right).

Position of the interface is $\zeta=\frac{2}{3}$. The exact solution is given by

$$
\begin{gathered}
p(x, t)= \begin{cases}\cos \left(\frac{10}{3}\right) \sin \left(\frac{4}{5} x\right) e^{-\frac{16}{25} t}, & x \leq \frac{2}{3}, \\
\sin \left(\frac{8}{15}\right) \cos (80(1-x)) e^{-\frac{16}{25} t}, & x>\frac{2}{3},\end{cases} \\
u(x, t)= \begin{cases}-\frac{5}{4} \cos \left(\frac{10}{3}\right) \cos \left(\frac{4}{5} x\right) e^{-\frac{16}{25} t}, & x \leq \frac{2}{3}, \\
-\frac{5 \cos \left(\frac{8}{15}\right)}{4 \tan \left(\frac{80}{3}\right)} \sin (80(1-x)) e^{-\frac{16}{25} t}, & x>\frac{2}{3} .\end{cases}
\end{gathered}
$$

Convergence results are summarized in Tables $9-12$. It is seen that convergence order does not depend on the jumps of coefficients (see also Fig.8). At the same time, on very coarse grids the numerical solution can give a bad approximation to the exact solution. This can be observed on Fig.7, where analytical and numerical solutions are plotted. 
300 A. Naumovich, O. Iliev, F. Gaspar, F. Lisbona, P. Vabishchevich

Table 9. Example 3: convergence in the maximum norm at $t=0.1$.

\begin{tabular}{llcccc}
\hline$h$ & $\tau$ & $\left\|\epsilon_{u}\right\|_{c}$ & $\left\|\epsilon_{p}\right\|_{c}$ & $\left\|\epsilon_{v}\right\|_{c}$ & $\left\|\epsilon_{s}\right\|_{c}$ \\
\hline $1 / 10$ & $1 / 10$ & $0.632 \mathrm{E} 00$ & $0.105 \mathrm{E} 01$ & $0.197 \mathrm{E} 02$ & $0.101 \mathrm{E} 01$ \\
$1 / 40$ & $1 / 40$ & $0.151 \mathrm{E} 00$ & $0.157 \mathrm{E} 00$ & $0.549 \mathrm{E} 01$ & $0.142 \mathrm{E} 00$ \\
$1 / 160$ & $1 / 160$ & $0.991 \mathrm{E}-02$ & $0.102 \mathrm{E}-01$ & $0.134 \mathrm{E} 01$ & $0.909 \mathrm{E}-02$ \\
$1 / 640$ & $1 / 640$ & $0.617 \mathrm{E}-03$ & $0.641 \mathrm{E}-03$ & $0.326 \mathrm{E} 00$ & $0.568 \mathrm{E}-03$ \\
$1 / 2560$ & $1 / 2560$ & $0.388 \mathrm{E}-04$ & $0.400 \mathrm{E}-04$ & $0.808 \mathrm{E}-01$ & $0.355 \mathrm{E}-04$ \\
\hline
\end{tabular}

Table 10. Example 3: convergence in the maximum norm at $t=1$.

\begin{tabular}{llcccc}
\hline$h$ & $\tau$ & $\left\|\epsilon_{u}\right\|_{c}$ & $\left\|\epsilon_{p}\right\|_{c}$ & $\left\|\epsilon_{v}\right\|_{c}$ & $\left\|\epsilon_{s}\right\|_{c}$ \\
\hline $1 / 10$ & $1 / 10$ & $0.155 \mathrm{E} 01$ & $0.138 \mathrm{E} 01$ & $0.189 \mathrm{E} 01$ & $0.114 \mathrm{E} 01$ \\
$1 / 40$ & $1 / 40$ & $0.185 \mathrm{E} 00$ & $0.380 \mathrm{E}-01$ & $0.867 \mathrm{E} 00$ & $0.401 \mathrm{E}-01$ \\
$1 / 160$ & $1 / 160$ & $0.138 \mathrm{E}-01$ & $0.413 \mathrm{E}-02$ & $0.165 \mathrm{E} 00$ & $0.401 \mathrm{E}-02$ \\
$1 / 640$ & $1 / 640$ & $0.811 \mathrm{E}-03$ & $0.226 \mathrm{E}-03$ & $0.379 \mathrm{E}-01$ & $0.224 \mathrm{E}-03$ \\
$1 / 2560$ & $1 / 2560$ & $0.496 \mathrm{E}-04$ & $0.135 \mathrm{E}-04$ & $0.928 \mathrm{E}-02$ & $0.136 \mathrm{E}-04$ \\
\hline
\end{tabular}

Table 11. Example 3: convergence in $L_{2}$ norm at $t=0.1$.

\begin{tabular}{llcccc}
\hline$h$ & $\tau$ & $\left\|\epsilon_{u}\right\|_{L_{2}}$ & $\left\|\epsilon_{p}\right\|_{L_{2}}$ & $\left\|\epsilon_{v}\right\|_{L_{2}}$ & $\left\|\epsilon_{s}\right\|_{L_{2}}$ \\
\hline $1 / 10$ & $1 / 10$ & $0.258 \mathrm{E} 00$ & $0.455 \mathrm{E} 00$ & $0.804 \mathrm{E} 01$ & $0.455 \mathrm{E} 00$ \\
$1 / 40$ & $1 / 40$ & $0.656 \mathrm{E}-01$ & $0.602 \mathrm{E}-01$ & $0.101 \mathrm{E} 01$ & $0.615 \mathrm{E}-01$ \\
$1 / 160$ & $1 / 160$ & $0.454 \mathrm{E}-02$ & $0.380 \mathrm{E}-02$ & $0.115 \mathrm{E} 00$ & $0.387 \mathrm{E}-02$ \\
$1 / 640$ & $1 / 640$ & $0.285 \mathrm{E}-03$ & $0.238 \mathrm{E}-03$ & $0.140 \mathrm{E}-01$ & $0.242 \mathrm{E}-03$ \\
$1 / 2560$ & $1 / 2560$ & $0.179 \mathrm{E}-04$ & $0.148 \mathrm{E}-04$ & $0.174 \mathrm{E}-02$ & $0.151 \mathrm{E}-04$ \\
\hline
\end{tabular}

Table 12. Example 3: convergence in $L_{2}$ norm at $t=1$.

\begin{tabular}{llcccc}
\hline$h$ & $\tau$ & $\left\|\epsilon_{u}\right\|_{L_{2}}$ & $\left\|\epsilon_{p}\right\|_{L_{2}}$ & $\left\|\epsilon_{v}\right\|_{L_{2}}$ & $\left\|\epsilon_{s}\right\|_{L_{2}}$ \\
\hline $1 / 10$ & $1 / 10$ & $0.843 \mathrm{E} 00$ & $0.542 \mathrm{E} 00$ & $0.754 \mathrm{E} 00$ & $0.521 \mathrm{E} 00$ \\
$1 / 40$ & $1 / 40$ & $0.757 \mathrm{E}-01$ & $0.823 \mathrm{E}-02$ & $0.204 \mathrm{E} 00$ & $0.819 \mathrm{E}-02$ \\
$1 / 160$ & $1 / 160$ & $0.480 \mathrm{E}-02$ & $0.123 \mathrm{E}-02$ & $0.186 \mathrm{E}-01$ & $0.124 \mathrm{E}-02$ \\
$1 / 640$ & $1 / 640$ & $0.296 \mathrm{E}-03$ & $0.773 \mathrm{E}-04$ & $0.209 \mathrm{E}-02$ & $0.774 \mathrm{E}-04$ \\
$1 / 2560$ & $1 / 2560$ & $0.184 \mathrm{E}-04$ & $0.481 \mathrm{E}-05$ & $0.254 \mathrm{E}-03$ & $0.481 \mathrm{E}-05$ \\
\hline
\end{tabular}



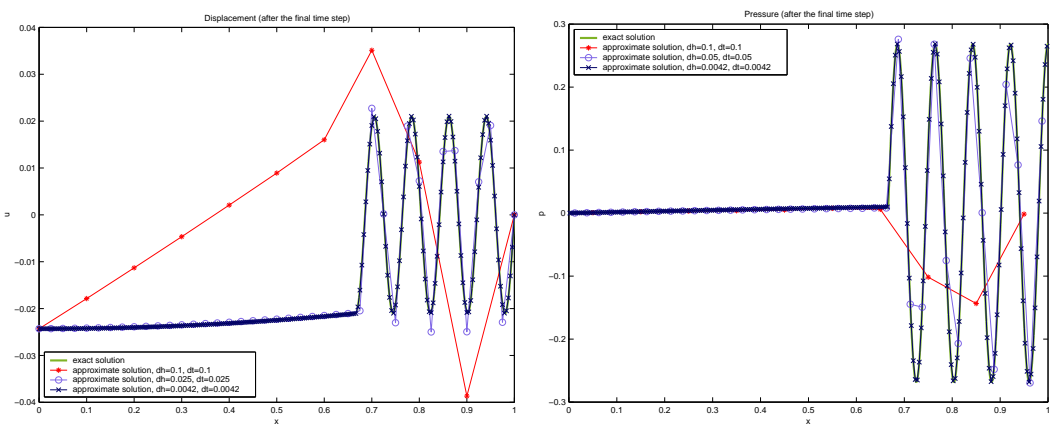

Figure 7. Example 3: convergence of displacement (left) and pressure (right).
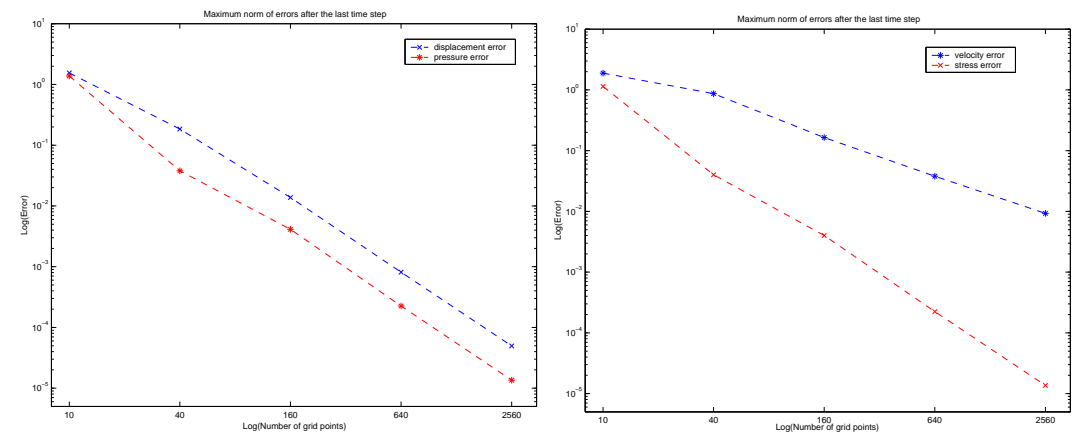

Figure 8. Example 3: errors in maximum norm for pressure and displacement (left) and velocity and stress (right).

\section{Case B: IBVP with no analytical solution known}

In the second set of numerical experiments we satisfy all boundary conditions and initial conditions corresponding to the continuous model. Let us consider the case when pore fluid is incompressible. In such situation initially the whole vertical load is taken by the pore fluid and there is a very little compression of the soil sample immediately after placing the load. This gives the following initial conditions:

$$
p(x, 0)=\sigma_{0}, \quad u(x, 0)=0 .
$$

Then during the consolidation process fluid pressure is dissipating and simultaneously effective stress of the solid is increasing.

There is no known analytical solution in this case and we only qualitatively compare our solutions with the results of other authors. Note that all parameters in the tests below are non-dimensional and all results are also plotted non-dimensionally.

Example 4. In this test material properties of layers are the following:

$$
k_{1}=1.0, \quad k_{2}=10.0, \quad \nu_{1}=1.0, \quad \nu_{2}=0.1 .
$$



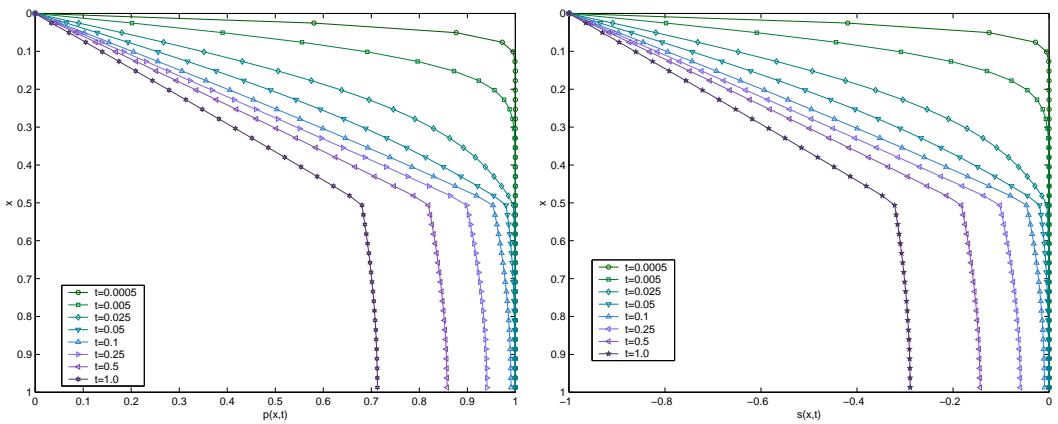

Figure 9. Example 4: Pore pressure (left) and stress (right) distribution in time.
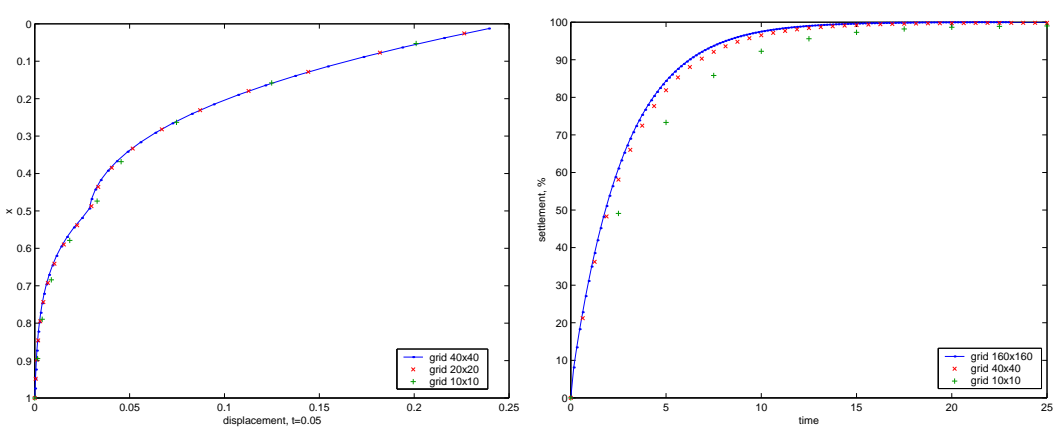

Figure 10. Example 4: Displacement in the profile (left) and rate of settlement of the soil surface (right).

It means that upper layer is ten times less permeable, but ten times stiffer. Figure 9 shows distributions of pore pressure and stress of the solid at different time moments. Remind that in this set of numerical experiments exact solution of the problem is unknown and we can not compare it with our numerical results, we can only analyze behaviour of the numerical solution during the grid thickening. Figure 10 shows displacement calculated on different grids at the fixed time moment $t=0.05$, and the rate of the settlement of the soil surface in time.

Example 5. In this test we change the location of layers from the previous example. Now upper layer is ten times more permeable and ten times less stiff. We use the following values of parameters:

$$
k_{1}=1.0, \quad k_{2}=0.1, \quad \nu_{1}=1.0, \quad \nu_{2}=10.0 .
$$

Some results of this experiment are plotted in Fig. 11.

Distributions of pore pressure and rate of settlement obtained in the previous two numerical experiments were compared to results published in the paper [11], and a very good qualitative agreement was observed. 

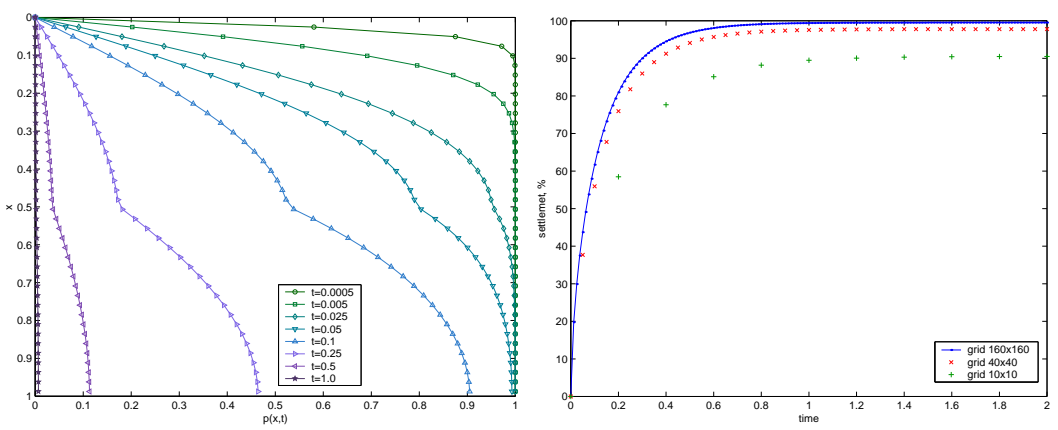

Figure 11. Example 5: Pressure distribution in time (left) and rate of settlement of the soil surface (right).

\section{Summary}

One dimensional poroelasticity problem with discontinuous coefficients is studied. No requirements about the location of the interface are posed (it is, in general, not aligned with the grid). Accurate finite volume discretization is derived. Various numerical experiments for the compressible and incompressible cases are performed in order to study numerically the convergence rate of the derived scheme for various combinations of the discontinuous coefficients.

In the existing publications no discussions on the order of convergence of the schemes for such problems was found, and the paper is filling this gap. In discrete $L_{2}$ norm we observe second order convergence for basic variables (pressure and displacements), as well as for fluxes (velocity and stress). In the maximum norm, first order convergence for velocity is observed, while all other variables converge with second order, independently of the location of the interface.

\section{Acknowledgments}

The research has been partially supported by the INTAS project 03-50-4395, the Spanish project MEC/FEDER MTM 2004-019051 and the Diputación General de Aragón.

\section{References}

[1] S.I. Barry and G.K. Aldis. Comparison of models for flow induced deformation of soft biological tissue. Australian defense force academy, Canberra, 1996.

[2] J. Bear and Y. Bachmat. Introduction to modelling of transport Phenomena in Porous Media. Kluwer Academic, Dordrecht, 1990.

[3] M. Biot. General theory of three dimensional consolidation. J. Appl. Phys., 12, 155 - 169, 1941.

[4] F.J. Gaspar, F.J. Lisbona and P.N. Vabischevich. A finite difference analysis of Biot's consolidation model. Appl. Num. Math., 44, 487-506, 2003. 
304 A. Naumovich, O. Iliev, F. Gaspar, F. Lisbona, P. Vabishchevich

[5] F.J. Gaspar, F.J. Lisbona and P.N. Vabischevich. A numerical model for radial flow through porous and deformable shells. CMAM, 4, 34-47, 2004.

[6] M.A. Koenders, S. Reymann and R.J. Wakeman. The intermediate stage of the dead-end filtration process. Chemical Engineering Science, 55, 3715 - 3728, 2000.

[7] M.A. Koenders and R.J. Wakeman. The initial stages of compact formation from suspensions by filtration. Chemical Engineering Science, 51(16), 3897 $3908,1996$.

[8] M.A. Koenders and R.J. Wakeman. Filter cake formation from structured suspensions. Trans IChemE, 75(Part A, March), 309 - 320, 1997.

[9] R.W. Lewis and B.A. Schrefler. The finite element method in the static and $d y$ namic deformation and consolidation of porous media. John Wiley, Chichester, 1998.

[10] L. Li. Theory of poroelastic structures with diffusion in the longitudinal directions. PhD thesis, Ben-Gurion University, Negev, US, 1997.

[11] I.C Pyrah. One-dimensional consolidation of layered soils. Geotechnique, 46(3), $555-560,1996$.

[12] A.A. Samarskii. Theory of difference schemes, Pure and Applied Mathematics. Marcel Dekker, New York, 2001.

[13] H.F. Wang. Theory of linear poroelasticity with application to geomechanics and hydrogeology. Princeton University Press, Princeton, 2000.

Skaitinis vienmačių lygčių poringai elastiškai terpei sprendimas daugiasluosnèje srityje

A. Naumovich, O. Iliev, F. Gaspar, F. Lisbona, P. Vabishchevich

Straipsnyje pateikta Bioto sistemos poringai elastiškai terpei daugiasluosnèje srityje diskretizacija baigtinių tūrių metodu. Norint išvengti skaitinio sprendinio ne fizinių osciliacijų atsirandančių naudojant kolokacinị tinklą, naudojamas judantis tinklas. Straipsnyje pateikti i̇vairūs skaitiniai eksperimentai iliustruoja baigtinių skirtumų schemos tikslumą. Pirmoje tokio eksperimento dalyje sprendžiami uždaviniai, turintys analizinius sprendinius, ir analizuojama greičio, slègio, išstūmimo, ittempiu artutinių sprendinių konvergavimo eilè. Antroje eksperimento dalyje pateikta skaitinis realiu procesu modeliavimas. 